\title{
Expression of pro-inflammatory cytokines in the auditory cortex of rats with salicylate-induced tinnitus
}

\author{
XIANG-HONG CHEN and LI-LI ZHENG
}

\begin{abstract}
Department of Endocrinology, The First Affiliated Hospital of Zhengzhou University, Zhengzhou, Henan 450052, P.R. China
\end{abstract}
Received September 26, 2016; Accepted June 6, 2017

DOI: $10.3892 / \mathrm{mmr} .2017 .7235$

\begin{abstract}
Tinnitus often results in severe psychological distress. The present study hypothesized that tinnitus acts as a chronic stressor and induces dysregulation of the production of cytokines. The gap pre-pulse inhibition of acoustic startle paradigm was applied to test tinnitus-like behavior in rats. Following this, the mRNA and protein expression levels of interferon (IFN)- $\gamma$, tumor necrosis factor (TNF)- $\alpha$, interleukin (IL)-6 and N-methyl D-aspartate receptor subunit 2A (NR2A) were measured in rats subjected to acute and chronic salicylate treatment, using reverse transcription-quantitative polymerase chain reaction and western blot analysis, respectively. The gap prepulse inhibition of acoustic startle paradigm detected the tinnitus-like behavior of rats. The expression of TNF- $\alpha$ and NR2A genes were increased in the auditory cortex (AC) following long-term administration of salicylate, whereas the expression of IFN- $\gamma$ genes decreased; however, the mRNA levels reversed back to normal baseline 14 days following the cease of salicylate administration. IL- 6 gene expression, however, was not fundamentally altered by salicylate treatment. The data demonstrated that chronic salicylate administration induces tinnitus, in part, via dysregulation of cytokines and specific membrane receptors in the AC.
\end{abstract}

\section{Introduction}

The active ingredient in the frequently used aspirin is salicylate, and previous studies and clinical examinations have demonstrated that it may result in reversible tinnitus. Salicylate-induced rats have previously been used as a model

Correspondence to: Professor Li-Li Zheng, Department of Endocrinology, The First Affiliated Hospital of Zhengzhou University, 1 Jianshe Eastern Road, Zhengzhou, Henan 450052, P.R. China E-mail: lilizheng66@126.com

Abbreviations: AC, auditory cortex; TNF- $\alpha$, tumor necrosis factor- $\alpha$; IL- 6 , interleukin- 6 ; IFN- $\gamma$, interferon- $\gamma$; NMDA, N-methylD-aspartate; NR2A, N-methyl D-aspartate receptor subunit 2A; GPIAS, gap prepulse inhibition of acoustic startle

Key words: tinnitus, cytokines, auditory cortex to study the disease (1-3). The use of salicylate for long periods of time has been known to result in the modification of the average spectrum of the electrophysiological cochleoneural activity $(4,5)$ distortion product otoacoustic emissions (6), increase outer hair cell electromotility $(3,7)$, and reliably induce tinnitus. It has previously been demonstrated that tinnitus may be linked to alterations at one or more points along the peripheral and/or central auditory pathways (8), and even non-auditory brain structures (9-11).

Patients who have suffered for numerous years from tinnitus subsequently suffer from depression and present with symptoms of distress $(12,13)$. The combination of tinnitus and stress creates a vicious cycle where the symptoms of each disease worsen. Anxiety and stress make the tinnitus worse which in turn, enhances the stress and anxiety (14). Further research has demonstrated that anxiety, stress and psychological distress are associated with alterations in the immune system (15-17). Uncontrollability of the stressor has been identified as a primary determinant of the immunological stress response (18), a characteristic that additionally applies to the condition of tinnitus. The present study therefore hypothesized that tinnitus, perceived as disturbing and uncontrollable, acts as a chronic stressor and thereby interferes with stress-associated cytokines and proteins. The hypothalamic-pituitary-adrenal axis and/or the sympathetic nervous system are activated by a stressor and dysregulation of the production of cytokines are induced by stressors, including interferon (IFN)- $\gamma$, tumor necrosis factor (TNF)- $\alpha$ and interleukin (IL)-6 (16). A stressor may additionally modulate N-methyl D-aspartate (NMDA) receptors (NMDARs) via glutamate (19). Increased inflammatory gene expression has been demonstrated in the cochlear nucleus in a rat model of tinnitus (20). However, there are few studies assessing the inflammatory genes in the auditory cortex (AC).

The present study detected the expression levels of IFN- $\gamma$, TNF- $\alpha$, IL- 6 and NR2A genes in the AC under conditions of salicylate exposure. To verify and detect the tinnitus behavior of the rats, gap prepulse inhibition of acoustic startle (GPIAS) standard was applied (21-23).

\section{Materials and methods}

Animals. The Animal Care and Use Committee of Zhengzhou University School of Medicine (Zhengzhou, China) approved the procedures. A total of 36 adult male Sprague-Dawley rats 
(age, 2-3 months; weight, 200-250 g) were purchased from Shanghai SLAC Laboratory Animal Co., Ltd. (Shanghai, China). Rats with normal pinna reflexes that did not have a middle ear infection were used in the present study. The animals were divided into 4 groups: i) Control group ( $n=10)$; ii) salicylate injected once $(n=6)$ acute treatment group; iii) continuous injections of salicylate for 7 days (Sal-7d/S7 n=10; ) sustained treatment group and iv) rehabilitation group with 14 days rest post-chronic salicylate administration for 7 days $(n=10$; $\mathrm{S} 7+\mathrm{R} 14)$. Rats were housed in a temperature-controlled room at $21 \pm 2^{\circ} \mathrm{C}$, with $55 \pm 3 \%$ relative humidity, under a 12 -h light/dark cycle with free access to water and food.

Experimental design and salicylate administration. Sodium salicylate (Sigma-Aldrich; Merck KGaA, Darmstadt, Germany) was melted to a density of $200 \mathrm{mg} / \mathrm{ml}$ in regular saline [9\% (w/v) $\mathrm{NaCI}$ ]. Rats in the acute group were administered an intraperitoneal (i.p.) injection of salicylate $(400 \mathrm{mg} / \mathrm{kg})$ and were sacrificed following 2 h. i.p injections of salicylate were administered to animals in the sustained treatment groups every day at 8:00 a.m. for 7 continuous days. The rehabilitating group received intraperitoneal injections for 7 continuous days and then underwent 14 days of recovery following completion of treatment (S7+R14). At 8:00 a.m. on day 7, the rats in S7 group were sacrificed, whereas the rats in the S7+R14 group were sacrificed at 8:00 a.m. on day $21(6,7)$. Rats were anesthetized with pentobarbital sodium $(60 \mathrm{mg} / \mathrm{kg})$ intraperitoneally (i.p.) prior to sacrifice.

Gap detection testing. The GPIAS paradigm was used to assess tinnitus as previously described $(20,21)$. The procedure utilizes acoustic starlet reflex tests within animals which have been given salicylate. GPIAS testing began two h prior to sacrifice. The rats were in an acoustically transparent cage placed over a sensitive piezoelectric transducer. The transducer produced voltage in proportion to the response of the rats, generated by a digital signal processor. The result of the reaction from the rats was recorded with a computer and analyzed offline.

The gap detection tests were conducted using different band-pass-filtered sounds. The reactions of starlet had been obtained with a $20 \mathrm{msec}$ spurt with white noise. The narrowband gap sound started $100 \mathrm{msec}$ prior to the broadband astonishing noise starting. Furthermore, the time between each sound was 30-35 sec (22).

GPIAS percentages were calculated as the average ratio of trials with a gap vs. trials without gaps, for each frequency, according to the following formula: [(AvgTnogap-AvgTgap)/ AvgTnogap x100\%], where AvgTgap was the average amplitude in the gap trials, and AvgTnogap was the average amplitude of trials without gaps $(23,24)$.

Reverse transcription-quantitative polymerase chain reaction (RT-qPCR). The AC was dissected following sacrifice of rats. TRIzol $^{\circledR}$ reagent (Invitrogen; Thermo Fisher Scientific, Inc., Waltham, MA, USA) was used to extract total RNA, following the manufacturer's protocol. The pureness and amount of isolated RNA had been measured at optical density (OD) 280 and OD260. Primers obtained from Sangon Biotech Co., Ltd. (Shanghai, China) were utilized in the amplification of IL-6, TNF- $\alpha$, NR2A, IFN- $\gamma$ and GAPDH as listed in Table I. Isolated
Table I. Primer sequences for reverse transcription-quantitative polymerase chain reaction.

Genes $\quad$ Primer sequence (5'-3')

TNF- $\alpha$

$\begin{array}{ll}\text { Forward } & \text { TCAGTTCCATGGCCCAGAC } \\ \text { Reverse } & \text { GTTGTCTTTGAGATCCATGCCATT }\end{array}$

IL-6

Forward

ATTGTATGAACAGCGATGATGCAC

Reverse CCAGGTAGAAACGGAACTCCAGA

IFN- $\gamma$

Forward

TGGATGCTATGGAAGGAAAGA

Reverse

GATTCTGGTGACAGCTGGTG

NR2A

Forward

TGGCTATCCTGCAGCTGTTTG

Reverse TGGCTGCTCATCACCTCATTC

GAPDH

Forward

GGCACAGTCAAGGCTGAGAATG

Reverse

ATGGTGGTGAAGACGCCAGTA

TNF- $\alpha$, tumor necrosis factor- $\alpha$; IL-6, interleukin-6; IFN- $\gamma$, interferon- $\gamma$; NR2A, N-methyl D-aspartate receptor subunit $2 \mathrm{~A}$.

RNA was reverse transcribed into cDNA using the PrimeScript RT Reagent kit (DRR037A; Takara Bio, Inc., Otsu, Japan) according to the manufacturer's instructions. The reverse transcription reaction was performed at $37^{\circ} \mathrm{C}$ for $15 \mathrm{~min}$, and at $85^{\circ} \mathrm{C}$ for $5 \mathrm{sec}$. SYBR Premix Ex Taq was used to perform the PCR amplification (DRR420A; Takara Bio, Inc.), which was conducted using ABI 7500 real time PCR systems (Applied Biosystems; Thermo Fisher Scientific, Inc.). The reaction mixture was amplified for $2 \mathrm{~min}$ at $50^{\circ} \mathrm{C}$ and for $3 \mathrm{sec}$ at $95^{\circ} \mathrm{C}$, followed by 40 cycles of $5 \mathrm{sec}$ at $95^{\circ} \mathrm{C}$, then $34 \mathrm{sec}$ at $60^{\circ} \mathrm{C}$. The optimal concentration of the templates and primers utilized within each reaction was established in accordance with the standard curve that was produced earlier to the response when it was equal to almost $100 \%$ of the reaction efficiency. In addition, relative calculations and quantifications were performed using comparative threshold cycle methods $\left(2^{-\Delta \Delta \mathrm{Cq}}\right)(25)$.

Western blotting. Total protein was extracted using radioimmunoprecipitation assay lysis buffer (Cell Signaling Technology Inc., Danvers, MA, USA) for $30 \mathrm{~min}$ on ice and the concentration was measured using a bicinchoninic acid protein assay. Equal amounts of extracted protein samples $(20 \mu \mathrm{g})$ were then loaded onto $8 \%(\mathrm{w} / \mathrm{v})$ SDS-PAGE for electrophoresis of NR2A protein, with $12 \%(\mathrm{w} / \mathrm{v})$ SDS-PAGE utilized for electrophoresis of IL- 6 , TNF- $\alpha$, and IFN- $\gamma$ proteins. The proteins were then transferred to polyvinylidene difluoride membranes. The membranes had been blocked within TBS containing $0.1 \%$ Tween-20 (TBST) and 5\% skimmed milk powder at room temperature for $4 \mathrm{~h}$. The membranes were then incubated overnight with primary antibodies at $4^{\circ} \mathrm{C}$ and washed with TBST. Secondary antibodies had been diluted with blocking buffer and incubated for $2 \mathrm{~h}$ with the membranes at room temperature. Finally, immunoreactive bands were imaged using the 


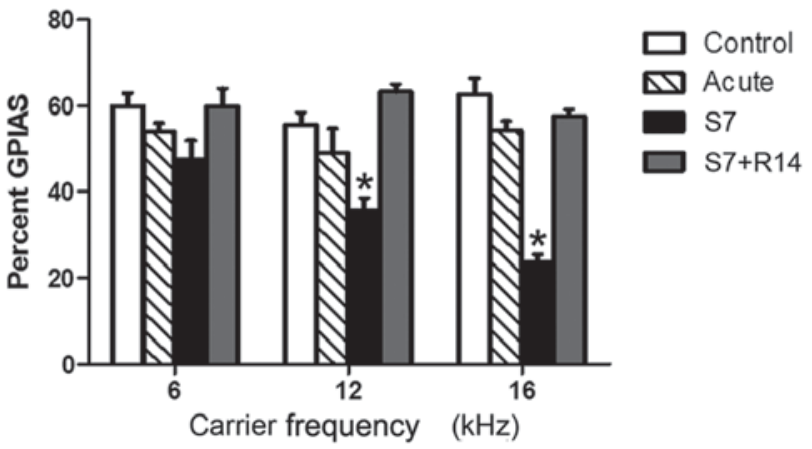

Figure 1. Effects of salicylate on GPIAS values. Rats in the S7 group demonstrated a significant decrease in GPIAS values compared with control group at 12 and $16 \mathrm{kHz}$, however not at $6 \mathrm{kHz}$. There was no difference in GPIAS values between rats in the acute treatment group, the 14 days following S7 group and the control group. ${ }^{*} \mathrm{P}<0.05$ vs. control. GPIAS, gap prepulse inhibition of acoustic startle; acute, salicylate injected once $(n=6)$ intense treatment group; S7, continuous injections of salicylate for 7 days $(n=10)$ sustained treatment group; S7+R14, rehabilitation group with 14-day rest post-chronic salicylate administration for 7 days $(n=10)$.

Super Signal Chemiluminescent Substrate system (Pierce; Thermo Fisher Scientific, Inc.). Blots were semi-quantified by densitometry using Image Lab software version 4.1 (Bio-Rad Laboratories, Inc., Hercules, CA, USA) and normalized to GAPDH.

The primary antibodies used were: mouse anti-IL-6 antibody (cat. no. ab9324; 1:1,000; Abcam, Cambridge, UK), mouse anti-TNF- $\alpha$ antibody (cat. no. ab1793; 1:1,000; Abcam), goat anti-IFN- $\gamma$ antibody (cat. no. AF-585-NA; 1:5,000; R\&D Systems Inc., Minneapolis, MN, USA), rabbit anti-NMDAR2A antibody (cat. no. D15B3; 1:1,000; Cell Signaling Technology Inc.) and rabbit anti-GAPDH antibody (cat. no. 5174S; 1:1,000; Cell Signaling Technology, Inc.). The secondary antibodies used were as follows: horseradish peroxidase (HRP)-conjugated goat anti-rabbit immunoglobulin (Ig)G (cat. no. 111-005-003; 1:5,000; Jackson ImmunoResearch Laboratories, Inc., West Grove, PA, USA), and HRP-conjugated goat anti-mouse IgG (cat. no. 115-005-062; 1:5,000; Jackson ImmunoResearch Laboratories, Inc.).

Statistical analysis. Data are presented as the mean \pm standard deviation of 6 independent experiments. Statistical analysis was performed using SPSS software version 19.0 (IBM Corp., Armonk, NY, USA). Based on the similarity of the variations and the distribution of the information, either a Kruskal-Wallis $\mathrm{H}$ test or one-way analysis of variance with a Bonferri post hoc test were used to compare the significance of the differences between the groups. $\mathrm{P}<0.05$ was considered to indicate a statistically significant difference.

\section{Results}

Tinnitus-like behaviour in rats is induced by salicylate. There had been an essential decline in GPIAS values in the $\mathrm{S} 7$ group when compared with control group at $12 \mathrm{kHz}(\mathrm{P}<0.05)$ and $16 \mathrm{kHz}(\mathrm{P}<0.05)$, however not at $6 \mathrm{kHz}(\mathrm{P}>0.05)$.

It was observed that the rats that appeared to be experiencing tinnitus were those that were accepting a repetitive injection of salicylate for 7 days. Conversely, it appeared that

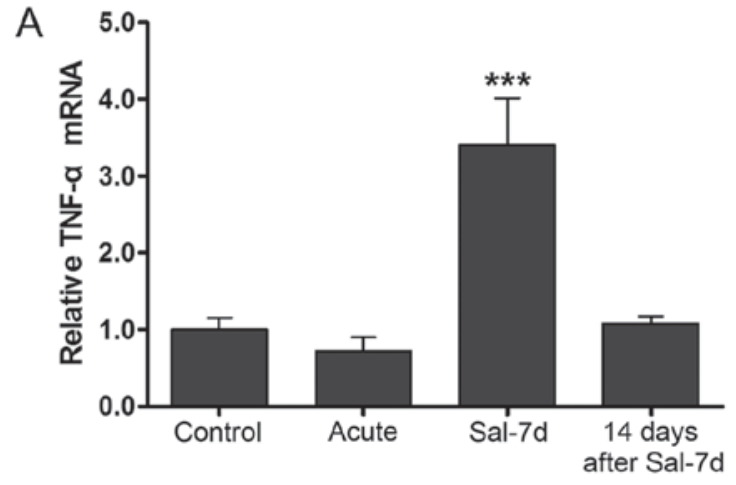

B
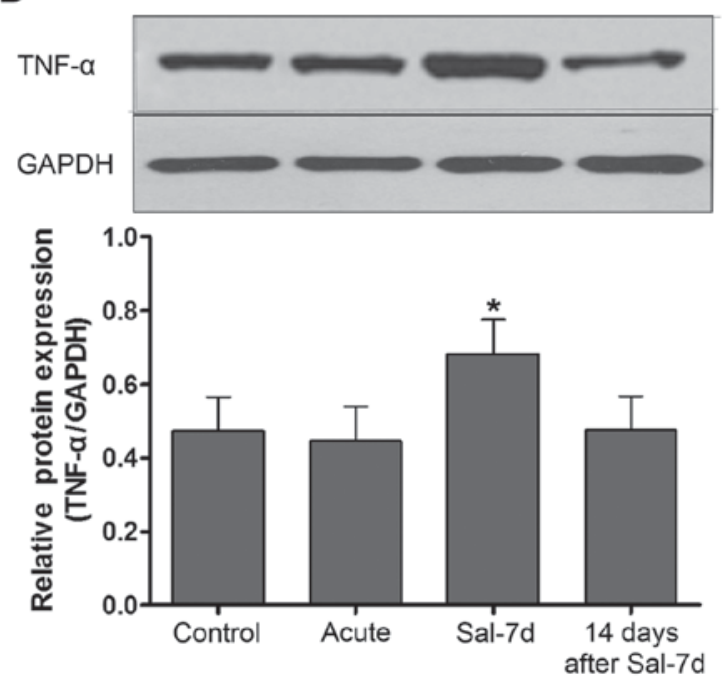

Figure 2. Expression of TNF- $\alpha$ in the auditory cortex. (A) Quantitative polymerase chain reaction demonstrated a significantly increased level of TNF- 0 mRNA in the S7 group compared with the control group, acute treatment group and 14 days following the S7 group. (B) Protein expression levels of TNF- $\alpha$, indicated by western blot analysis, were markedly increased in the S7 group compared with other groups. ${ }^{*} \mathrm{P}<0.05 ;{ }^{*}{ }^{* *} \mathrm{P}<0.001$ vs. all groups $\mathrm{TNF}-\alpha$, tumor necrosis factor; acute, salicylate injected once $(n=6)$ intense treatment group; S7, continuous injections of salicylate for 7 days $(n=10)$ sustained treatment group; S7+R14, rehabilitation group with 14-day rest post-chronic salicylate administration for 7 days $(n=10)$.

there were no differences between the acute treatment group, S7+R14 group and control group values $(\mathrm{P}>0.05)$, indicating that tinnitus-like behavior was not induced with salicylate injected only once, and that the tinnitus-like behavior induced in the S7 group vanished 14 days following the end of the salicylate treatment period (Fig. 1).

TNF- $\alpha$ expression levels increase in the AC. TNF- $\alpha$ gene expression was upregulated in the $\mathrm{AC}$ of the rats which had been chronically treated with salicylate for 7 days $(\mathrm{P}<0.05)$. There were no alterations in the precise treatment or $\mathrm{S} 7+\mathrm{R} 14$ groups (Fig. 2).

IL-6 expression levels remain unaltered in the AC. IL-6 mRNA and protein expression was not significantly altered in any of the treatment groups compared with control (Fig. 3).

IFN- $\gamma$ expression decreases in the AC. Compared with control group, IFN- $\gamma$ gene expression was downregulated in the AC of rats which had been chronically treated with salicylate for 
A

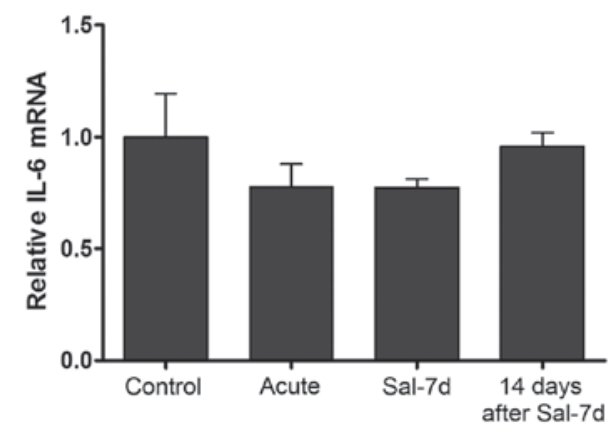

B
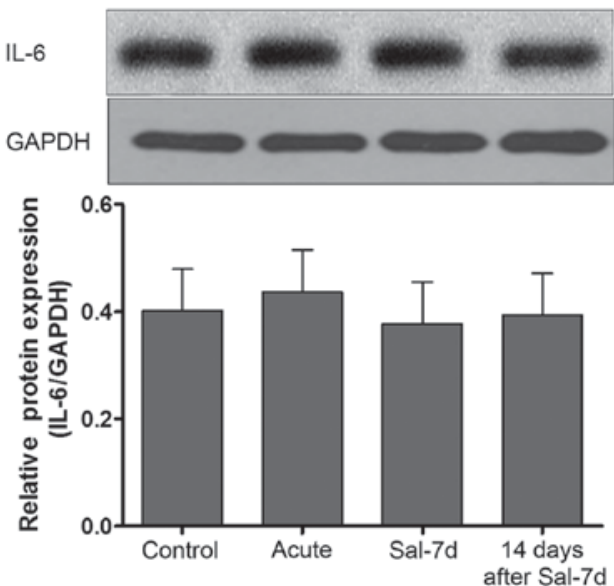

Figure 3. Expression of IL-6 in the cochlear nucleus. Differences in the expression levels of IL-6 (A) mRNA and (B) protein in the AC. Compared with control group, IL-6 gene expression exhibited no significant alterations in any of the groups. IL, interleukin; acute, salicylate injected once $(\mathrm{n}=6)$ intense treatment group; S7, continuous injections of salicylate for 7 days $(n=10)$ sustained treatment group; S7+R14, rehabilitation group with 14-day rest post-chronic salicylate administration for 7 days $(n=10)$.

A

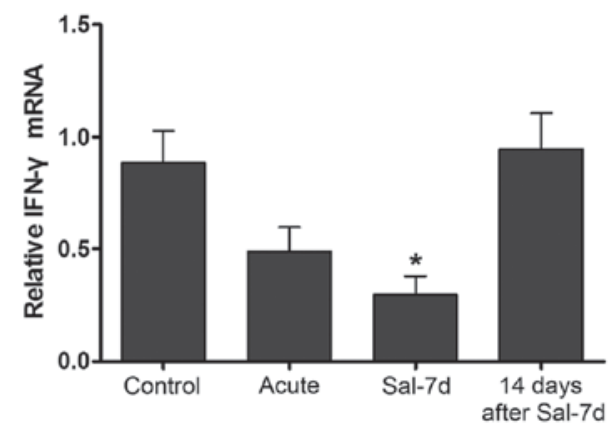

B
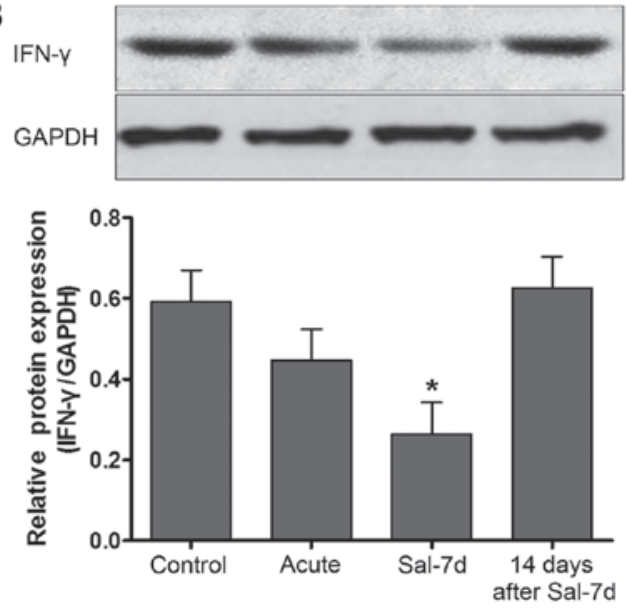

Figure 4. Expression of IFN- $\gamma$ in the auditory cortex. (A) Quantitative polymerase chain reaction demonstrated a significantly decreased level of IFN- $\gamma$ mRNA in the S7 group compared with control, acute treatment and 14 days following S7 groups. (B) IFN- $\gamma$ protein expression level, as indicated by western blot analysis, was significantly decreased in the $\mathrm{S} 7$ group compared with other groups. "P $<0.05$ vs. all groups. IFN- $\gamma$, interferon- $\gamma$; acute, salicylate injected once $(\mathrm{n}=6)$ intense treatment group; S7, continuous injections of salicylate for 7 days $(\mathrm{n}=10)$ sustained treatment group; S7+R14, rehabilitation group with 14-day rest post-chronic salicylate administration for 7 days $(n=10)$.

A

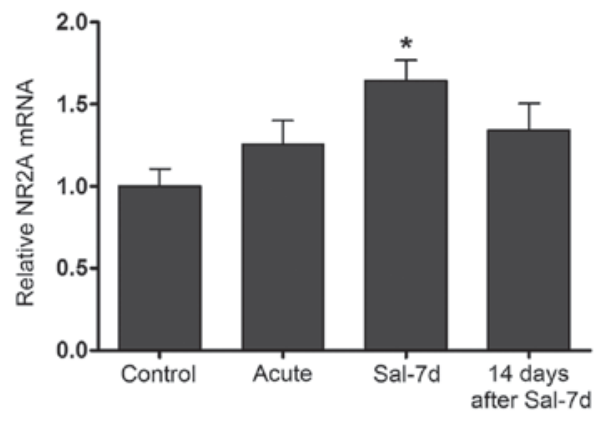

B
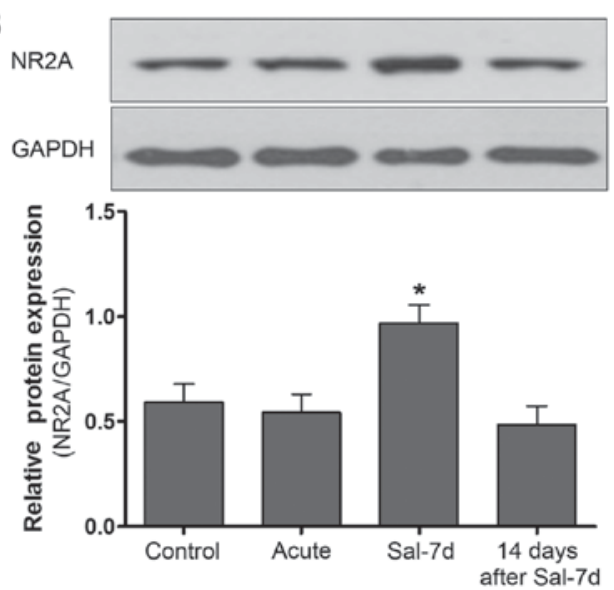

Figure 5. Expression of NR2A in the auditory cortex. The expression levels of NR2A (A) mRNA and (B) protein were significantly increased in the S7 group compared with control, acute treatment and 14 days following S7 groups, as determined by quantitative polymerase chain reaction and western blot analysis. "P<0.05 vs. all groups. NR2A, N-methyl D-aspartate receptor subunit $2 \mathrm{~A}$; acute, salicylate injected once $(\mathrm{n}=6)$ intense treatment group; $\mathrm{S} 7$, continuous injections of salicylate for 7 days $(n=10)$ sustained treatment group; $S 7+R 14$, rehabilitation group with 14-day rest post-chronic salicylate administration for 7 days $(n=10)$. 
7 days $(\mathrm{P}<0.05)$ There were no significant IFN- $\gamma$ gene expression alterations in the precise treatment and S7+R14 groups (Fig. 4).

NR2A expression is upregulated in the AC. qPCR and western blot analysis were conducted in order to detect the expression of NR2A in the AC. As presented in Fig. 5, levels of NR2A mRNA and protein expression were upregulated in rats which had been chronically treated with salicylate for 7 days $(\mathrm{P}<0.05)$, compared with control group. Furthermore, no increase was observed in the precise treatment or the S7+R14 groups.

\section{Discussion}

The 'theory of cochlear origin' suggest that tinnitus originates from the central nervous system. A previous study using positron emission tomography revealed an increase in metabolic activity and continuous neuronal activation in the $\mathrm{AC}$ of rats with salicylate-induced tinnitus (2).

Salicylate affects neural activity in the brain, particularly in the AC (26). In addition, a strong association is present between stress and perception of tinnitus. The present study demonstrated that the expression of TNF- $\alpha$ and NR2A genes increased in the $\mathrm{AC}$ following long-term administration of salicylate, whereas the expression of IFN- $\gamma$ genes decreased, however returned to normal levels when salicylate treatment ceased. Additionally, the results demonstrated that IL-6 gene expression was not fundamentally altered by salicylate.

Tinnitus has previously been demonstrated to be connected with the activity of NMDA receptors (27-29). It was demonstrated that NR2A mRNA and protein expression increased significantly under the conditions of long-term administration of salicylate in the $\mathrm{AC}$, and recovered back to normal levels 14 days following termination of salicylate treatment.

The results mimic those of a previous study that demonstrated NR2A is upregulated in the AC of rats that experience tinnitus (30). The etiology of tinnitus is associated with glutamate-induced excitotoxicity. NMDARs are important in excitotoxic injury (31). As modulatory subunits, the overall neurotransmission excitability in the $\mathrm{AC}$ is enhanced by the upregulation of NR2A receptors.

NMDAR activation, accompanied by ascending $\mathrm{Ca}^{2+}$ influx, stimulation of $\mathrm{Ca}^{2+}$-dependent enzymes, ATP depletion and an increase in lipid peroxidation products, contributes to the excitotoxic damage in the auditory system under conditions of salicylate administration.

A biphasic model proposed by Dhabhar and McEwen (32) evaluates type of stress (acute or chronic) and how it affects the immune response. TNF- $\alpha$ reacts to acute stress in mice models (33), in addition to psychological stress in humans (34). Salicylate has been demonstrated to reduce the expression of TNF- $\alpha$ by inhibition of NFAT-mediated transcription in lymphocytic and monocytic cell lines (35). However, the results of the present study indicated that TNF- $\alpha$ gene expression increased reversibly in the $\mathrm{AC}$ of rats with tinnitus induced by long-term salicylate administration. These findings suggested that TNF- $\alpha$ may serve as a stress marker in tinnitus patients (36). TNF- $\alpha$ shifts neurons towards increased excitation and decreased inhibition (37). TNF- $\alpha$ enhances spontaneous excitatory synaptic transmission in retinotectal neurons (38) and in chronic pain;
TNF- $\alpha$ may therefore participate in the hyperactivity of the AC in tinnitus. A previous study reported an interaction between TNF- $\alpha$ and NMDARs (39).

The results of the present study demonstrated that NR2A and TNF- $\alpha$ were upregulated in the AC following chronic administration of salicylate. NR2A and TNF- $\alpha$ levels exhibited the same alterations in expression levels. Therefore, TNF- $\alpha$ may potentially contribute to tinnitus via augmentation of NMDAR expression and/or function.

Transient increases of IL-6 may be provoked psychological stressors. In plasma, stress and administration of adrenaline may increase levels of IL-6. It has previously been suggested that increased IL-6 levels are connected with psychological stress and primary depressive disorders (40). However, no alterations in IL-6 expression levels are detected in patients with tinnitus prior to, during, or following relaxation training (35), which is in accordance with the absence of alterations demonstrated in the present study. The role of IL-6 in the pathogenesis of tinnitus remains to be fully elucidated.

IFN- $\gamma$ gene expression was downregulated in the AC of rats that were chronically administered salicylate for 7 days. Psychological stressors decrease IFN- $\gamma$ levels during exam stress (41). The decreased IFN- $\gamma$ has also been attributed to the pharmacological actions of salicylate (36), and an increase in NMDARs (42). It is revealed in these data that chronic salicylate administration induces dysregulation of cytokines and NR2A, which may be involved in tinnitus.

In conclusion, the present results demonstrate that transient alterations are produced by chronically administered salicylate, in the expression of cytokines in the AC. These data suggest that alterations in neural plasticity in the AC may result from long-term administration of salicylate.

\section{References}

1. Jastreboff PJ, Brennan JF, Coleman JK and Sasaki CT: Phantom auditory sensation in rats: An animal model for tinnitus. Behav Neurosci 102: 811-822, 1988.

2. Paul AK, Lobarinas E, Simmons R, Wack D, Luisi JC, Spernyak J, Mazurchuk R, Abdel-Nabi H and Salvi R: Metabolic imaging of rat brain during pharmacologically-induced tinnitus. Neuroimage 44: 312-318, 2009.

3. Yu N, Zhu ML, Johnson B, Liu YP, Jones RO and Zhao HB: Prestin up-regulation in chronic salicylate (aspirin) administration: An implication of functional dependence of prestin expression. Cell Mol Life Sci 65: 2407-2418, 2008.

4. Cazals Y and Huang ZW: Average spectrum of cochlear activity: A possible synchronized firing, its olivo-cochlear feedback and alterations under anesthesia. Hear Res 101: 81-92, 1996.

5. Cazals Y, Horner KC and Huang ZW: Alterations in average spectrum of cochleoneural activity by long-term salicylate treatment in the guinea pig: A plausible index of tinnitus. J Neurophysiol 80: 2113-2120, 1998 .

6. Huang ZW, Luo Y, Wu Z, Tao Z, Jones RO and Zhao HB: Paradoxical enhancement of active cochlear mechanics in longterm administration of salicylate. J Neurophysiol 93: 2053-2061, 2005.

7. Yang K, Huang ZW, Liu ZQ, Xiao BK and Peng JH: Long-term administration of salicylate enhances prestin expression in rat cochlea. Int J Audiol 48: 18-23, 2009.

8. Noreña AJ and Farley BJ: Tinnitus-related neural activity: Theories of generation, propagation, and centralization. Hear Res 295: 161-171, 2013.

9. Kraus KS and Canlon B: Neuronal connectivity and interactions between the auditory and limbic systems. Effects of noise and tinnitus. Hear Res 288: 34-46, 2012.

10. Leaver AM, Renier L, Chevillet MA, Morgan S, Kim HJ and Rauschecker JP: Dysregulation of limbic and auditory networks in tinnitus. Neuron 69: 33-43, 2011. 
11. Rauschecker JP, Leaver AM and Mühlau M: Tuning out the noise: Limbic-auditory interactions in tinnitus. Neuron 66: 819-826, 2010.

12. Bartels H, Staal MJ and Albers FW: Tinnitus and neural plasticity of the brain. Otol Neurotol 28: 178-184, 2007.

13. Milerová J, Anders M, Dvořák T, Sand PG, Königer S and Langguth B: The influence of psychological factors on tinnitus severity. Gen Hosp Psychiatry 35: 412-416, 2013.

14. Fioretti AB, Fusetti M and Eibenstein A: Association between sleep disorders, hyperacusis and tinnitus: Evaluation with tinnitus questionnaires. Noise Health 15: 91-95, 2013.

15. Segerstrom SC and Miller GE: Psychological stress and the human immune system: A meta-analytic study of 30 years of inquiry. Psychol Bull 130: 601-630, 2004

16. Glaser R and Kiecolt-Glaser JK: Stress-induced immune dysfunction: Implications for health. Nat Rev Immunol 5: 243-251, 2005.

17. Yang EV and Glaser R: Stress-induced immunomodulation and the implications for health. Int Immunopharmacol 2: 315-324, 2002.

18. Peters ML, Godaert GL, Ballieux RE, Brosschot JF, Sweep FC, Swinkels LM, van Vliet M and Heijnen CJ: Immune responses to experimental stress: Effects of mental effort and uncontrollability. Psychosom Med 61: 513-524, 1999.

19. Bennett A O MR: Stress and anxiety in schizophrenia and depression: Glucocorticoids, corticotropin-releasing hormone and synapse regression. Aust N Z J Psychiatry 42: 995-1002, 2008.

20. Hu SS, Mei L, Chen JY, Huang ZW and Wu H: Effects of salicylate on the inflammatory genes expression and synaptic ultrastructure in the cochlear nucleus of rats. Inflammation 37: 365-373, 2014

21. Lobarinas E, Hayes SH and Allman BL: The gap-startle paradigm for tinnitus screening in animal models: Limitations and optimization. Hear Res 295: 150-160, 2013.

22. Engineer ND, Riley JR, Seale JD, Vrana WA, Shetake JA, Sudanagunta SP, Borland MS and Kilgard MP: Reversing pathological neural activity using targeted plasticity. Nature 470 : 101-104, 2011.

23. Yang G, Lobarinas E, Zhang L, Turner J, Stolzberg D, Salvi R and Sun W: Salicylate induced tinnitus: Behavioral measures and neural activity in auditory cortex of awake rats. Hear Res 226 : 244-253, 2007

24. Su YY, Luo B, Jin Y, Wu SH, Lobarinas E, Salvi RJ and Chen L: Altered neuronal intrinsic properties and reduced synaptic transmission of the rat's medial geniculate body in salicylate-induced tinnitus. PLoS One 7: e46969, 2012

25. Livak KJ and Schmittgen TD: Analysis of relative gene expression data using real-time quantitative PCR and the 2(-Delta Delta C(T)) method. Methods 25: 402-408, 2001

26. Stolzberg D, Salvi RJ and Allman BL: Salicylate toxicity model of tinnitus. Front Syst Neurosci 6: 28, 2012.

27. Ruel J, Chabbert C, Nouvian R, Bendris R, Eybalin M, Leger CL, Bourien J, Mersel M and Puel JL: Salicylate enables cochlear arachidonic-acid-sensitive NMDA receptor responses. J Neurosci 28: 7313-7323, 2008.
28. Guitton MJ, Caston J, Ruel J, Johnson RM, Pujol R and Puel JL: Salicylate induces tinnitus through activation of cochlear NMDA receptors. J Neurosci 23: 3944-3952, 2003.

29. Peng BG, Chen S and Lin X: Aspirin selectively augmented $\mathrm{N}$-methyl-D-aspartate types of glutamate responses in cultured spiral ganglion neurons of mice. Neurosci Lett 343: 21-24, 2003

30. Jia MH and Qin ZB: Expression of c-fos and NR2A in auditory cortex of rats experienced tinnitus. Zhonghua Er Bi Yan Hou Tou Jing Wai Ke Za Zhi 41: 451-454, 2006 (In Chinese).

31. Zhang Y, Su P, Liang P, Liu T, Liu X, Liu XY, Zhang B, Han T, Zhu YB, Yin DM, et al: The DREAM protein negatively regulates the NMDA receptor through interaction with the NR1 subunit. J Neurosci 30: 7575-7586, 2010.

32. Dhabhar FS and McEwen BS: Acute stress enhances while chronic stress suppresses cell-mediated immunity in vivo: A potential role for leukocyte trafficking. Brain Behav Immun 11: 286-306, 1997.

33. Yamasu K, Shimada Y, Sakaizumi M, Soma G and Mizuno D: Activation of the systemic production of tumor necrosis factor after exposure to acute stress. Eur Cytokine Netw 3: 391-398, 1992.

34. Maes M, Song C, Lin A, De Jongh R, Van Gastel A, Kenis G, Bosmans E, De Meester I, Benoy I, Neels H, et al: The effects of psychological stress on humans: Increased production of pro-inflammatory cytokines and a Th1-like response in stressinduced anxiety. Cytokine 10: 313-318, 1998.

35. Aceves M, Dueñas A, Gómez C, San Vicente E, Crespo MS and García-Rodríguez C: A new pharmacological effect of salicylates: Inhibition of NFAT-dependent transcription. J Immunol 173: 5721-5729, 2004

36. Weber C, Arck P, Mazurek B and Klapp BF: Impact of a relaxation training on psychometric and immunologic parameters in tinnitus sufferers. J Psychosom Res 52: 29-33, 2002.

37. Stellwagen D and Malenka RC: Synaptic scaling mediated by glial TNF-alpha. Nature 440: 1054-1059, 2006.

38. Lee RH, Mills EA, Schwartz N, Bell MR, Deeg KE, Ruthazer ES, Marsh-Armstrong N and Aizenman CD: Neurodevelopmental effects of chronic exposure to elevated levels of pro-inflammatory cytokines in a developing visual system. Neural Dev 5: 2, 2010.

39. Park KM and Bowers WJ: Tumor necrosis factor-alpha mediated signaling in neuronal homeostasis and dysfunction. Cell Signal 22: 977-983, 2010.

40. Seidel A, Arolt V, Hunstiger M, Rink L, Behnisch A and Kirchner H: Cytokine production and serum proteins in depression. Scand J Immunol 41: 534-538, 1995.

41. Marshall GD Jr, Agarwal SK, Lloyd C, Cohen L, Henninger EM and Morris GJ: Cytokine dysregulation associated with exam stress in healthy medical students. Brain Behav Immun 12: 297-307, 1998

42. Mashkina AP, Cizkova D, Vanicky I and Boldyrev AA: NMDA receptors are expressed in lymphocytes activated both in vitro and in vivo. Cell Mol Neurobiol 30: 901-907, 2010. 